\title{
MORPHOLOGICAL AND STRUCTURAL CHARACTERIZATION OF POLY(3-DECYLTHIOPHENE) PREPARED BY ELECTROPOLYMERIZATION USING 1-BUTYL-3-METHYL-IMIDAZOLIUMTETRAFLUORBORATE AS SOLVENT
}

\author{
SUHEY TORRES, GLORIA NECULQUEO, FRANCISCO MARTÍNEZ \\ Departamento de Ciencia de los Materiales, Facultad de Ciencias Físicas y Matemáticas, \\ Universidad de Chile. Casilla 2777. Santiago-Chile \\ (Received $28^{\text {th }}$ February $2007-$ Accepted $24^{\text {th }}$ May 2007)
}

\begin{abstract}
In this paper, we report the electrochemical polymerization of 3-decylthiophene at room temperature using the 1-butyl-3-methylimidazoliumtetrafluorborate as solvent. The polymer film is electroactive and its morphology depends upon the anode used. The polymerized 3-decylthiophene was characterized by ft-infrared, uv-visible, thermal gravimetric analysis and conductivity measurement.
\end{abstract}

Keywords: polythiophene, electropolymerization, ionic solvent, conducting polymer

\section{INTRODUCTION}

The electrochemical polymerization of thiophene is apparently similar to that of pyrrole and studies have been reported since several years by Tourillon and Garnier $^{1}$ and by Kaneto et $\mathrm{al}^{2,3}$. The polymer under these conditions is insoluble and usually amorphous. Substitution of a single 3-position leads to a marked increase in regularity and poly (alkylthiophene) are more regular polymer with grater stability to stability cycling ${ }^{4}$. Many poly alkylthiophene have been prepared using different synthetic routes ${ }^{5,7}$ and very stable polythiophene films can be deposited electrochemically on ITO glass or platinum electrode and can be switched very rapidly from highly doped to less doped states, with a strong change in absorbance and they have been investigated for use in various electro optical applications ${ }^{8,9}$. Besides these properties, its environmental stability and good electrical and optical properties make the polyalkylthiophene very promising material.

The use of a solvent of ionic type can be a great contribution in the obtaining of conducting polymers, since they have high ionic conductivities and are very stable. During the last 5 years a remarkable progress in the synthesis of ionic liquids has been achieved and now several companies offer these products on the market. In recent literature, electropolymerization of pyrrol ${ }^{11}$ 3,4-ethylened ioxythiophene ${ }^{12}$ and benzen $\mathrm{e}^{13}$ have been reported.

In this work, we present the polymerization of 3-decylthiophene by using 1-butyl-3-methyl-imidazoliumtetrafluorborate as solvent. In contrast with other electrochemical system used in this kind of monomers, no additional electrolyte is needed and the reaction can be carried out under mild conditions at room temperature.

\section{EXPERIMENTAL}

The 3-decylthiophene was prepared by the cross coupling reaction of the Grignard of 2-bromothiophene with 1-bromodecane, using the Ni(dppp) dichloride catalyst following the Kumada synthesis ${ }^{14}$. To an electrochemical cell of two compartments, separated by a fritted glass with a platinum anode $0.69 \mathrm{~g}$. of 3-decylthiophene and $20 \mathrm{ml}$. of a mixture of the ionic liquid/dichloromethane, 50:50 were added under argon atmosphere. A constant current density of 2 $\mathrm{mA} / \mathrm{cm}^{2}$ was applied during 4 hrs. and a black-bluish film was deposited on the electrode. The film was removed from the electrode surface and washed thoroughly with acetonitrile, methanol and then dried under vacuum at $50^{\circ} \mathrm{C}$ during 6 hrs. $0.2 \mathrm{~g}$ (yield $28 \%$ ) of the poly thiophene was obtained from the platinum electrode. The four point method for conductivity was performed on the film and was also characterized by FT-infrared, SEM microscopy, TGA and UV-visible.

\section{RESULTS AND DISCUSSION}

Fig. 1 shows the UV-visible spectra of both monomer and polymer obtained by the electrochemical polymerization using platinum electrode as anode. Clearly it is observed a shift of the maximum absorption peak due to the monomer $245,6 \mathrm{~nm}$ towards a longer wavelength of $427,6 \mathrm{~nm}\left(\mathrm{CHCl}_{3}\right)$ a much more conjugated structure which can be considered as minimum of 4 monomeric units, if we compare with the wavelength of thiophene oligomers previously reported, whose absorption ranges between 300 to $434 \mathrm{~nm}\left(\mathrm{CHCl}_{3}\right)$, from bithiophene to sexithiophene ${ }^{15,16}$. The pending alkyl chain of 10 carbons in position 3 of thiophene ring, presents a high steric hindrance between polythiophene rings, so normally the aromatic rings are twisted so the alkyl groups lie on opposite side facilitating the conjugation length through the rings. However, the fact of being able to obtain a self standing polymer film assures the presence of polymer structure. Fig. 2 and 3 correspond to the infrared of the monomer and polymer structure, respectively

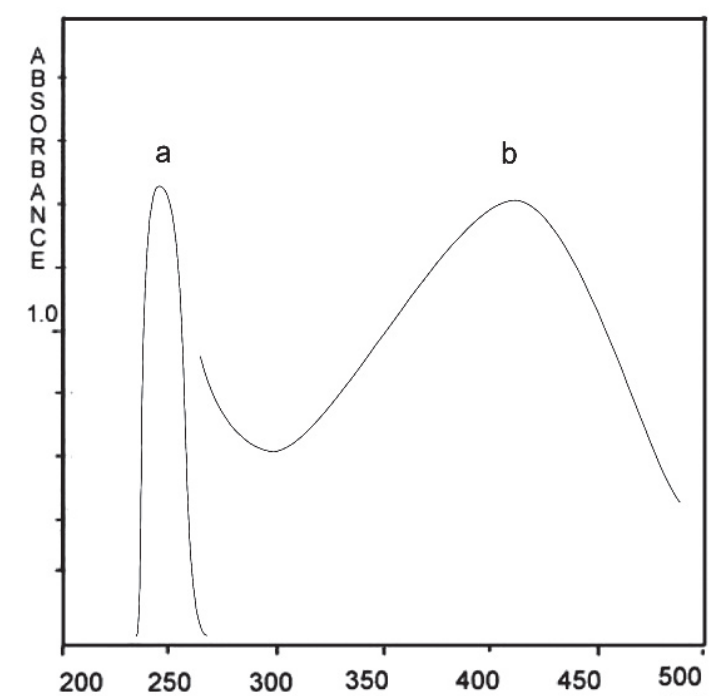

Fig.1 UV-visible spectrum of monomer (a) and Poly (3-decylthiophene) (b)

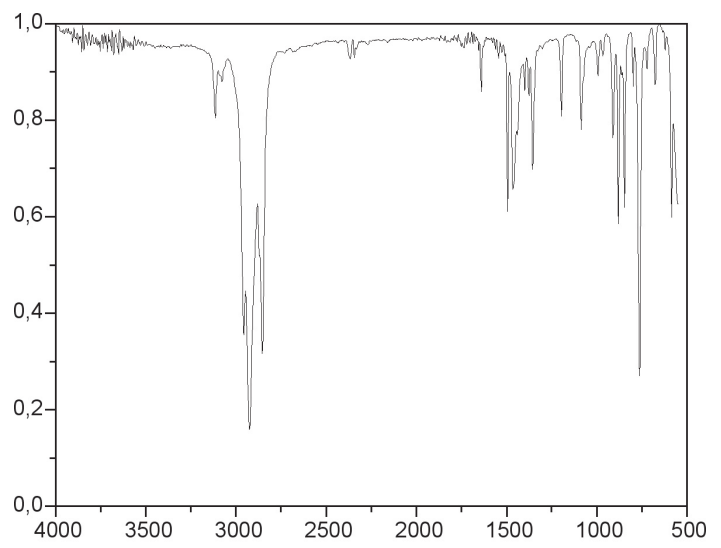

Fig. 2 Infrared spectrum of monomer 3-decylthiophene 


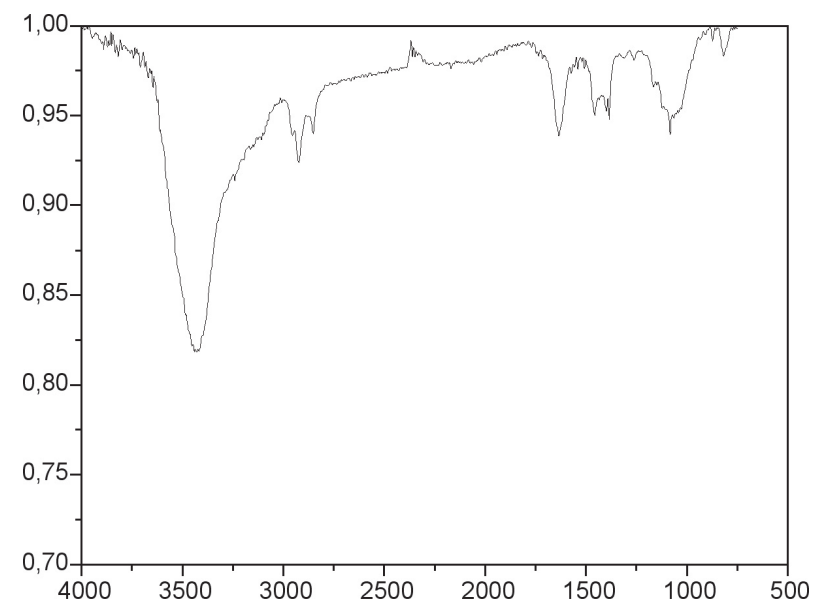

Fig. 3 Infrared spectrum of poly (3-decylthiophene)

The stretching of C-H saturated alkyl chain can be clearly seen at 2850$2950 \mathrm{~cm}^{-1}$ in both monomer and polymer spectra. The band at $798 \mathrm{~cm}^{-1}$ ( Fig. 3 ) corresponds to the $\mathrm{C}-\mathrm{H}$ bending, characteristic of 2,5 thiophene substituted ring. The infrared of the polymer film shows broad bands, characteristic of polymer structure, however a wide and strong band at the region $3350-3450 \mathrm{~cm}$ ${ }^{-1}$ is observed, associated to $\mathrm{O}-\mathrm{H}$ stretching bond . This band could be considered as some residual methanol on the polymer product from the washing to remove the ionic solvent. A partially oxidation, cannot also be discarded, in order to explain the $\mathrm{O}-\mathrm{H}$ band, further experiments are in progress to clarify this result.

The surface of the film electrodeposited on the platinum electrode was observed by SEM microscopy and is shown in Fig. 4. The film consists of a uniform globular morphology with grain diameter of about $10 \mu \mathrm{m}$. Experiments under progress carried out using ITO glass as electrode show a much more regular and uniform surface morphology

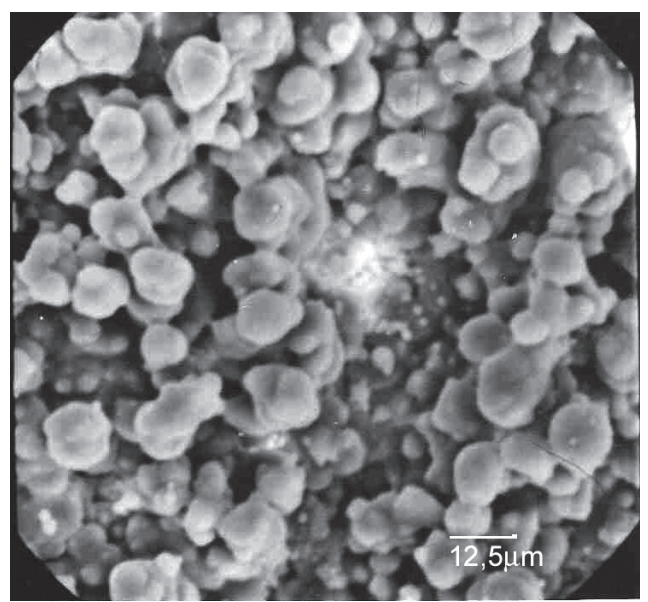

Fig. 4 SEM microphotography of the electropolymerized film of poly(3decylthiophene) on platinum electrode

The electrical conductivity of the film was measured by the four point method and the conductivity was $9.8 \times 10^{-5} \mathrm{~S} / \mathrm{cm}$. Although this values is lower compared with other electropolymerized polyalkythiophene, is good enough for a film or organic material as semiconductor one.

The thermal stability of the film was also studied. A thermal gravimetric analysis shown in Fig. 5 shows the high stability of this material. At ca. $300^{\circ} \mathrm{C}$ only $10 \%$ of the weight loss is observed and at ca. $478^{\circ} \mathrm{C}$ still remain $60 \%$ of the compound. Above $400^{\circ} \mathrm{C}$ starts a significant weight loss of the sample and over $500^{\circ} \mathrm{C}$ a complete decomposition occurs. This result corroborates other studies performed on alkylthiophenes which are known to be very stable at high temperature making them useful for various applications.

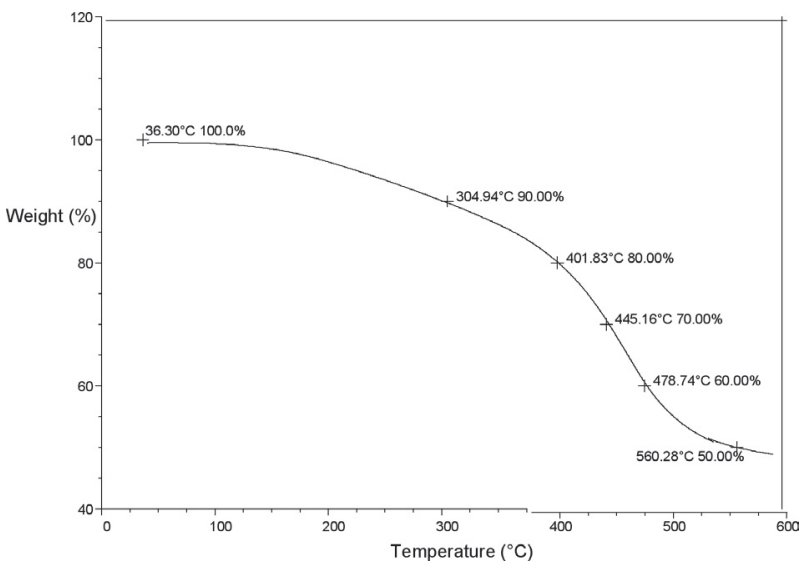

Fig. 5 TGA thermogram of poly(3-decylthiophene)

\section{CONCLUSIONS}

We can conclude that the polymerization of the 3-decylthiophene is possible to perform in an ionic liquid through electrochemical conditions at constant current density. The polymer presents an intrinsic conductivity and a great thermal stability. These results encourage to experiment with different thiophene derivatives or precursors which are of great motivation to follow with the development and investigation of electroactive materials with interesting and promising properties, through a fast and clean method of electroobtention.

\section{AKCNOWLEDGMENTS}

Authors wish to thank to Project Fondecyt 1040728 for financial aid.

\section{REFERENCES}

1. G. Tourillon, F. Garnier, J. Electroanal. Chem. 135, 173(1982); J. Phys. Chem. 87, 2289 (1983); J. Electroanal. Chem. 161(51), 407(1984).

2. K. Kaneto, I. Kohno, K. Yoshino, I. Inuishi. J. Chem. Soc.: Chem. Commun. 382(1983).

3. K. Kaneto, K. Yoshino, I. Inuishi, Japan J. Appl. Phys. L21, 567, (1982); L2, 412(1983).

4. F. Garnier, G. Tourillon, N. Gazard, J. C. Dubois. J. Electroanal. Chem. 148, 299(1983).

5. S. Hotta, S. D. D. V. Rughhooputh, A. J. Heeger, F. Wudl, Macromolecules. 20, 212 (1987).

6. M. Leclerc, F. Martinez, G. Wegner. Makromol. Chem. 190, 310 (1989).

7. Z. Bao. Adv. Mater. 2000, 12(3), 227 (2000).

8. H. E. Katz, Z. N. Bao, S. L. Gilat. Acc. Chem. Res. 34(5), 359 (2001).9. U. Mitschke, P. Bäuerle. J. Chem. Soc. Perkin Trans. 1. 7, 740 (2001).

10. M. R. Andersson, O. Thomas, W. Mammo, M. Svensson, M. Theander, O. Inganäs. J. Mater. Chem. 9, 1933 (1999).

11. J. H. Mazurkiewicz, P. C. Innis, G. G. Wallace, D. R. MacFarlane, M. Forsyth, Synt. Met.135, 31 (2003).

12. H. Randriamahazaka. C.Pesse, D. Teyssié, C. Chevrot. Electrochem. Commun. 6, 299 (2004).

13. S. Zein, El Abedin, N. Borissenko, F. Endres. Electr. Commun. 6, 422 (2004).

14. K. Tamao, S. Kodama, I. Makajima, M. Kumada. Tetrahedron, 38, 3347 (1982).

15. F. Martinez, R. Voelkel, D. Naegele, H. Naarmann, H. Mol. Cryst. Liq. Cryst. 167, 227(1989); F. Martínez, G. Neculqueo, M. E. Veas, Bol. Soc. Chil. Quím. 45, 53 (2000).

16. F. Martinez, G. Neculqueo, M. E. Veas. Bol. Soc. Chil. Quím. 45(1), 53 (2000). 